\title{
EM BUSCA DAS BASES ONTOLÓGICAS DA PSICOLOGIA DE VYGOTSKY
}

\author{
Francisca Maurilene do Carmo ${ }^{1}$ \\ Universidade Federal da Paraíba, João Pessoa-PB, Brasil \\ Susana Vasconcelos Jimenez \\ Universidade Estadual do Ceará, Fortaleza-CE, Brasil
}

\begin{abstract}
RESUMO. O estudo busca estabelecer os fundamentos ontológicos do pensamento de Vygotsky, indicando que a construção teórica erigida pelo e autor está centrada no trabalho, como o complexo que deu origem ao homem como ser social. Tal postulado seria consistente com os princípios do marxismo recuperado por Lukács como uma ontologia do ser social, superadora da tradição metafísica e idealista, firmando, nesse sentido, o caráter radicalmente histórico da essência humana. Apontam-se os equívocos fundamentais operado pelo neovygotskianismo, o qual, tratando as categorias vygotskianas da linguagem, cultura e interação apartadas do princípio marxiano do trabalho, acaba por isolar Vygotsky do campo ontológico e, por extensão, do projeto socialista. Reafirma-se, por fim, que, não obstante a explícita relevância atribuída à dimensão metodológica do marxismo, está pressuposto na obra de Vygotsky, o substrato ontológico sobre o qual se funda o método de Marx.
\end{abstract}

Palavras-chave: Vygotsky; marxismo; ontologia.

\section{SEARCHING FOR THE ONTOLOGICAL BASES OF VYGOTSKY'S PSYCHOLOGY}

\begin{abstract}
The study seeks to establish the ontological foundation of Vygotsky's thought, indicating that his theoretical construct is centered upon labor, as the complex which originated man as a social being. This postulate would be consistent with the principles of Marxism, recoveved by Lukács as an ontology of the social being that goes far beyond the metaphysical and idealistic tradition, to assert the radically historical character of human essence. It denounces the fundamental mistakes operated by neovygotskianism, which, treating Vygotskian categories of language, culture and interaction, apart from the Marxist principle of work, ends up by isolating Vygotsky from the Marxian ontological realm, and, by extension, from the socialist project. It is finally reassured that, despite the explicit relevance attributed by Vygotsky to the methodological dimension of Marxism, it is presupposed in the context of his work, the ontological core, which founds Marx's method.
\end{abstract}

Key words: Vygotsky; Marxism; ontology.

\section{EN BUSCA DE LAS BASES ONTOLÓGICAS DE LA PSICOLOGÍA DE VYGOTSKY}

RESUMEN. El estudio busca establecer el fundamento ontológico del pensamiento de Vygotsky, indicando que su construcción teórica se centra en el trabajo como el complejo que originó el hombre como un ser social. Este postulado es consistente con los principios del marxismo, recuperado por Lukács como uma ontología del ser social queva mucho más allá de la tradición metafísica e idealista, para afirmar el carácter radicalmente histórico de la esencia humana. Denuncia los errores fundamentales operados por el neovygotskianismo, que, tratando las categorias vygotskianas de la lenguage, cultura e interacción, apartadas del principio marxista del trabajo, termina aislando Vygotsky de la esfera del marxismo ontológico y, por extensión, del proyecto socialista. Finalmente se aseguró que, apesar de la relevância explícita atribuída por Vigotski a la dimensión metodológica del marxismo, se presupone en el contexto de su obra, el núcleo ontológico que funda el método de Marx.

Palabras-clave: Vygotsky; marxismo; ontología..

O estudo aqui apresentado intenta articularse ao reduzido, porém significativo acervo de produções que se contrapõem à forma indébita como vem sendo predominantemente apropriada e divulgada a obra de Vygotsky - como, a rigor, todo o escopo da Psicologia Histórico-Cultural -

1 Endereço para correspondência: Rua Sidney Clemente Dore, 100, ap. 601, Tambaú, CEP 58.039-230, João Pessoa-PB. E-mail: jacklinerabelo@uol.com.br 
e que, no Brasil, está representada por autores como Tuleski (2001); Duarte (2000); Martins (2006), dentre outros, que buscam resgatar o aporte da tradição marxista nos escritos do psicólogo russo.

Em linhas gerais, esse seleto conjunto de autores atesta que a divulgação majoritária da produção intelectual deste grande nome da psicologia mundial estabelece-se através de alguns grandes cortes operados sobre sua teoria. Os dois primeiros cortes, devidamente situados por Tuleski (2001), diriam respeito, em primeiro plano, à aversão burguesa referente à formação comunista do autor e, em segundo, à censura stalinista de suas obras operada na década de 1930.

Reportando-nos, de modo mais particular, à persecução stalinista, é oportuno lembrar que, em 1936, dois anos após a morte de Vygotsky, o decreto Sobre as perversões pedológicas no sistema de comissariado do povo para a educação, escorrendo diretamente da pena de Stalin, trouxe consequências drásticas ao campo da nascente psicologia, banindo importantes psicólogos, dentre eles, Vygotsky, da cena cientifica soviética. Nesse contexto, agudiza-se o ataque pessoal a Vygotsky, iniciado, ainda no percurso de sua vida. Desse modo, o golpe decisivo aplicado a Vygotsky foi desferido naquele exato ano de 1936, quando, literalmente por decreto, seus livros foram removidos in totum das bibliotecas. As informações contidas no parágrafo foram, em larga medida, atestadas por Ludmila Obukhova, por ocasião da palestra proferida pela pesquisadora russa, na I Conferência Internacional: o enfoque históricocultural em questão, ocorrida em 2006, em Santo André, SP.

Aproximadamente trinta anos após a promulgação daquele paradigmático decreto, as obras de Vygotsky voltam a ser publicadas em seu país. Todavia, como anota Tuleski (2001), nessa retomada, foi operada “... uma seleção de seus textos que teriam interesse maior para o período de 'abertura' da União Soviética, excluindo-se grande parte dos trabalhos de Vygotsky, onde o mesmo tecia críticas à forma de organização que a sociedade soviética acabou por assumir após a morte de Lênin" ( $p$. 18).

O retorno da obra de Vygotsky à URSS é acompanhado de princípio, por uma tímida e inexpressiva divulgação do seu nome no Ocidente, motivada não só pela rejeição a uma psicologia que se supunha contaminada pelo stalinismo, como pelo preconceito em torno do próprio marxismo.

$\mathrm{Na}$ verdade, a empreitada de inscrever o nome de Vygotsky no Ocidente operou-se, particularmente, a partir dos Estados Unidos, no início da década de 1960, através de psicólogos do porte de Jerome Bruner e Michael Cole (Burgess, 1995; Newman e Holzman, 2002), que cuidaram, respectivamente, da tradução das obras Pensamento e Linguagem e A Formação Social da Mente. Nessas condições, destacam Duarte (2001) e Tuleski (2001) que, pelas mãos de seus tradutores e organizadores, a obra de Vygotsky foi severamente retalhada e distorcida. Para Burgess (1995), por exemplo, Bruner, "retiraria os conceitos [vygotskianos] de sua estrutura marxista para colocá-los no pragmatismo norte-americano" (p. 47). Newman e Holzman (2002), por sua vez, não obstante reconheçam o importante papel ocupado por Cole na divulgação da psicologia soviética no Ocidente, põem em questão o rigor teórico no trato da obra vigotskiana por ele empreendido. Ainda mais, aportando no Brasil, entre a segunda metade da década de 1970 e o início dos anos de 1980, predominantemente associada à linha editorial desenvolvida nos Estados Unidos, como anotam Mainardes e Pino (2000), a obra de Vygotsky vulgarizou-se, em expressiva medida, em leituras heterogêneas, superficiais e apartadas de sua fundamentação marxista. Contrariando essa tendência geral, devemos recuperar aqui, a importância primordial de Silvia Lane na introdução do legado vigotskiano no Brasil, na justa perspectiva marxista. De acordo com Sawaia (2006), o encontro de Lane com a psicologia histórico-cultural de Vigotski representava o seu encontro anterior com o marxismo.

Isso posto, poderíamos sopesar, então, que um terceiro corte desferido à herança de Vygotsky, decorrente, em uma larga acepção, à censura stalinista, por um lado, e à burguesa, por outro, operaria no plano da psicopedagogia burguesa contemporânea. A propósito dessa terceira incisão, asseveramos, ademais, a partir da divulgação da obra do psicologo soviético na contemporaneidade, que a mesma vai encontrar assento, na disseminação da proposta pedagógica construtivista ou socioconstrutivista.

Nesse contexto, sob efeito do paradigma pós-moderno, a produção de Vygotsky é manipulada no sentido da legitimação do projeto 
educacional construtivista, indo, por essa via, de encontro à consolidação da perspectiva psicopedagógica marxista de Vygotsky e ao seu compromisso intransigente com a edificação da sociedade comunista, a única que, em sua compreensão, possibilitando ao homem, "dar esse enorme salto adiante - do reino da necessidade ao reino da liberdade" (Vygotsky, 1998 , p. 120), permitiria o desenvolvimento pleno das individualidades.

Tem razão Elhammoumi (2010) quando anota que aqueles que buscam apreender as idéias de Vygotsky não podem deixar de enfrentar obstáculos de monta, os quais se devem, de forma mais pungente, aos desvios mistificadores de seu pensamento, operados através das confabulações de um número de psicólogos cognitivistas e antropologistas culturalistas dos anos 1960 e 1970. A esse arranjo alinhavado de aportes teóricos veio acoplar-se, ademais, o ideário do chamado socioconstrutivisimo, em cujo campo, é oportuno observar, Vygotsky é perfilado em íntima associação com Piaget.

Para Elhammoumi (2010), sem dúvida, a psicologia sócio-cultural desenvolvida por Vygotsky traduziria uma extensão dos escritos de Marx e Engels - enquanto, conforme admite oportunamente 0 mesmo autor, Piaget encontraria em Kant, sua fonte de inspiração. Por conseguinte, "qualquer tentativa de modificar o uso que Vygotsky faz das idéias de Marx com algum elemento estranho não é apenas objetivamente anti-Vygotsky, mas, também a distorção de sua teoria" (Elhammoumi, 2010, p. 661). Por esse mesmo prisma, outrossim, não deixa o autor de postar o legado de Vygotsky em direta contraposição ao dogmatismo que atravessou em tão larga medida, a tradição marxista. Na incisiva declaração do autor (2010), em tradução livre, "Vygotsky foi um oponente destemido do dogmatismo na tradição marxista." (p. 662).

Nesse preciso sentido, passamos a assumir, ao lado dos autores supracitados, a tarefa de confirmar a inscrição de Vygotsky na agenda marxista, resgatando o complexo conceitual vigotskiano, em referência às premissas fundamentais do marxismo recuperado por Lukács, como uma ontologia do ser social, qual seja, aquela ontologia materialista superadora das deformações que vitimaram o pensamento de Marx, fundamentalmente a partir da Segunda Internacional e que, como assinala Oldrini
(1999), acabaram por cruzar-se com "o objetivismo ossificado, enrijecido, dogmático do stalinismo" (p. 67).

Nesse contexto, o marxismo teria assumido uma feição economicista, estabelecendo uma "relação causal entre estrutura e superestrutura, economia e ideologia, com a consequente redução do marxismo a um rígido determinismo" (Oldrini, 1999, p. 69); ou, em outras palavras, supondo a economia como o determinante absoluto das demais esferas da realidade social. Tertulian (1996), por sua vez, além de repisar o abominável economicismo, ressalta a "tendência do marxismo dogmático, em privilegiar a categoria da necessidade, tornando hipertrófico seu papel na história" (p. 61).

Diante desse conjunto de elementos, a empreitada de cavar as bases ontológicas do pensamento de Vygotsky materializou-se como objeto de um compreensivo projeto investigativo, sobre cujos resultados, necessariamente abertos e rigorosamente preliminares, funda-se 0 presente artigo.

A investigação que está na base desta exposição elegeu, como objetivo maior, examinar em que medida a afiliação de Vygotsky ao universo categorial do marxismo teria ultrapassado a esfera estritamente metodológica/gnoseológica. Colocando a questão em termos mais precisos, tentamos aferir se, além de perseguir a lógica dialética impressa no método indicado por Marx, Vygotsky teria pressuposto uma visão ontologicamente perspectivada acerca da essência humana, o que significa o mesmo que indagar em que dimensão teria nosso psicólogo concebido o ser social em sua gênese e reprodução, em consonância com as coordenadas explicitadas por Lukács, a partir de Marx.

É oportuno registrar que, na tentativa de cumprir nossa monumental tarefa, deparamonos com uma questão deveras espinhosa, uma vez que o próprio Vygotsky realça repetidamente e com indubitável justeza, a importância primacial do método.

Este seria o método de Marx, o qual se situaria, para Vygotsky, inversamente à ontologia metafísica, de cujas garras tentava o autor resgatar a ciência psicológica. Ainda assim, ou seja, mesmo diante da ênfase atribuída à perspectiva metodológica, em refutação a qualquer axioma da esfera da ontologia, achamos por bem averiguar se estaria pressuposto em Vygotsky, o fundamento 
ontológico do método de Marx, no sentido recuperado por Lukács.

É nossa convicção, com efeito, que as tantas distorções de cunho logicista, mecanicista e determinista, atestadas por Tertulian (1996) e Oldrini, (1999), dentre outros, imputadas ao legado marxiano, se deveriam, em significativa medida, ao fato de se ter descolado desse método, sua prioridade ontológica. Nesse sentido, julgamos cabível a indagação: não seria legítimo postular que o método de Marx, se, ontologicamente oco, muito bem se prestaria aos oportunismos de ocasião, fundados invariavelmente na expressão dogmática de umas ou outras exatas opiniões, que Vygotsky soube tão bem condenar?

Cabe-nos, então, reafirmar a importância de se resgatar o pressuposto ontológico da obra vygotskiana, inquirindo em que medida sua aversão à consideração ontológica estaria assente àquelas ontologias dominantes no seu tempo histórico, as quais, como aluiu o próprio Lukács, teriam operado o completo esmaecimento do ser.

\section{ELEMENTOS DE COMPREENSÃO DO MARXISMO COMO UMA ONTOLOGIA DO SER SOCIAL}

Efetivamente, referindo-se às ontologias prémarxianas, que antecederam à ontologia de novo tipo fundada por Marx, Lukács (2011) reconhecia com a devida clareza, que "o essencial do ser empalideceu totalmente nas antigas ontologias, por vezes desapareceu totalmente, ou, nos casos favoráveis, constituiu apenas um elemento, muitas vezes quase imperceptível, na consideração em seu conjunto" (p. 37).

Confirma Lessa (1996), por seu turno, que a ontologia que Lukács vai resgatar na obra de Marx se constitui como "uma grande novidade se confrontada com a metafísica tradicional" (p. 8). Essa novidade consistiria, exatamente, na suposição da radical historicidade da essência humana e da possibilidade da emancipação dos homens mediante a superação do capital.

Foi, reconhecidamente, Lukács aquele que, a rigor, identificou a presença de uma ontologia na obra marxiana, a dizer, apreendeu o edifício categorial erigido por Marx como uma teoria da generidade humana.

Elementos deveras importantes estariam na base da virada ontológica de Lukács, como demarca Tertulian (1996), com a devida propriedade:

Diante do neopositivismo - que tendia a reduzir a realidade à sua compreensão cognitiva, ... enquanto se libertava dos problemas ontológicos atribuindo-os à esfera da "metafísica" - ele [Lukács] pretendia restabelecer a autonomia ontológica do real, a sua totalidade intensiva e a sua irredutibilidade à pura manipulação (p. 61, aspas do autor).

Nesse sentido, é justo reiterar com o mesmo pensador, que a Ontologia do Ser Social cumpriu o objetivo de

superar duas deformações simétricas do pensamento de Marx .... O determinismo unívoco, que absolutiza o poder do fator econômico, tirando a eficácia dos outros complexos da vida social, é condenado com rigor não inferior àquele usado para condenar a interpretação teleológica, que, por sua parte, fetichiza a necessidade ao considerar toda formação social ou toda ação histórica como um passo no caminho para a realização de um fim imanente ou transcendente (Tertulian, 1996, p. 60).

Ao empreender o resgate ontológico do marxismo, em verdade, Lukács elucidou que é o homem como ser social, em sua complexíssima gênese e desenvolvimento, o mais autêntico objeto de pesquisa de Marx. Para Lukács, Marx teria, assim, estipulado, para além de qualquer improbabilidade, a essência onto-histórica do homem, fundada no trabalho, pelo qual, este transforma o meio natural, cria o novo e se cria como um ser radicalmente novo.

Faz-se, aqui, necessário recuperar na já clássica formulação de Marx que abaixo reproduzimos, aquela que se constitui o fundamento da ontologia marxiana, a categoria trabalho:

Antes de tudo, o trabalho é um processo de que participam o homem e a natureza, processo em que o ser humano com sua própria ação, impulsiona, regula e controla seu intercâmbio material com a natureza. Defronta-se com a natureza como uma de suas forças. Põe em movimento as forças naturais de seu corpo, braços e pernas, cabeças e mãos, a fim de apropriar-se dos recursos na natureza, 
imprimindo-lhes forma útil à vida humana. Atuando assim sobre a natureza externa e modificando-a, ao mesmo tempo modifica sua própria natureza. Desenvolve as potencialidades nela adormecidas e submete ao seu domínio o jogo das forças naturais (Marx, 1989, p. 202).

Desse modo, estaria posta a categoria que funda o mundo dos homens, uma vez que "somente o trabalho tem, como sua essência ontológica, um claro caráter intermediário", ou seja, "ele é, essencialmente, uma interrelação entre homem (sociedade) e natureza, tanto inorgânica ... como orgânica, interrelação que ... antes de mais nada assinala a passagem no homem que trabalha, do ser meramente biológico ao ser social" (Lukács, traduzido por Tonet, s/d, p. 3).

Vale recolocar que, pondo a termo as três esferas ontológicas que compõem o cosmo inorgânica, orgânica e social - Lukács assevera que o trabalho traz à luz uma nova qualidade de ser, que, sem perder o vínculo com as esferas inorgânica e orgânica, passa a reger-se por uma legalidade própria, aquela que alcança a dimensão de um ser que se desprendeu do determinismo natural, tornando-se capaz de ação consciente e livre, com todos os heterogêneos e contraditórios desdobramentos que instituem a evolução histórica dos homens, como, em última análise, o homem como sujeito de seu devir. Convém avançar um pouco mais em nossas brevíssimas colocações no terreno da ontologia do ser social para lembrar que, num processo de complexificação contínua e dinâmica, o trabalho põe incessantemente novas necessidades, para cuja resolução, surgem e se desenvolvem os múltiplos complexos sociais que configuram a práxis humana, a exemplo da linguagem, da ciência, da educação, da arte, da política etc. Não há que se perder de vista, outrossim, que cada um dos demais complexos sociais mantém com o trabalho, uma relação de dependência ontológica e de autonomia relativa e, só assim, poderia assumir sua função própria no processo de reprodução social. Os diferentes complexos mantêm, por fim, com o trabalho, uma relação de determinação recíproca, influenciando-se mutuamente sob o primado da totalidade social. A sociedade define-se, agora, rigorosamente, como um complexo de complexos, sepultando, definitivamente, o economicismo e o fatalismo, como atinentes ao pensamento de Marx.

\section{VYGOTSKY E A CONTRAPOSIÇÃO À ONTOLOGIA METAFÍSICA}

Retomando, então, a questão lançada anteriormente, qual seria o sentido de se identificar a vinculação da obra de Vygotsky, com os pilares da nova ontologia inaugurada por Marx e recuperada por Lukács? Sua declarada adesão aos fundamentos do marxismo e sua predestinada rigorosidade quanto à aplicação do método de Marx já não seriam suficientes para delimitar a circunscrição do seu campo teórico? Por que, em última análise, tentar ultrapassar o campo metodológico e adentrar no terreno da ontologia, precisamente a ontologia do ser social, a ontologia marxiana, em referência à psicologia vygotskiana?

Quase que a comprovar a relevância das indagações fundamentais que conduziram nossa investigação, Costa (2010) recobra que "a radicalidade de Marx está em compreender o movimento do real para transformá-lo revolucionariamente, de acordo com as possibilidades engendradas pelo ser social criado pela atividade humana", postulando, a seguir, com muita propriedade: "Assim, só partindo desse pressuposto, será possível entender os limites, contradições e contribuições dos próprios herdeiros de Marx..., além de evidenciar as possibilidades concretas do marxismo como instrumento de emancipação humana" (p. 197).

Ora, conforme entendemos a questão, apreender a perspectiva ontológica latente na obra do importante herdeiro de Marx que aqui enfocamos sinaliza impreterivelmente para o horizonte da revolução socialista e para a radical transformação do estado vigente das coisas.

Tal orientação revolucionária marcou a produção teórica, como a trajetória de vida de Vygotsky, que não hesitou em enfrentar as grandes questões no campo da psicologia, tendo como horizonte maior "a formação de um novo tipo de homem" e a "elevação de toda a humanidade a um nível mais alto de vida social" (Vygotsky, 1998, p. 120).

Cabe assinalar, ademais, que, afrontando a crise da psicologia, Vygotsky (1999) opõe-se a qualquer perspectiva de resolução dos problemas que se situe, igualmente, no âmbito 
da gnoseologia e da ontologia tomada como filosofia metafísica, assentada nos preceitos do idealismo. Aprofundando suas reflexões sobre a aludida crise, acaba por firmar o primado do ser sobre o conhecer, fincando salutar distância do subjetivismo, ao mesmo tempo em que coloca a objetividade para além do empiricismo. É isto, em suma, que está posto pelo autor na preciosa citação decalcada do Significado histórico da crise da psicologia, escrito em 1927, que registramos abaixo.

A confusão entre o problema gnoseológico e o ontológico resultante da transposição para a psicologia de conclusões já estabelecidas, em vez de realizar a partir dela todo o processo de raciocínio, provoca a deformação de um ou de outro problema. Quando isto é feito, é comum identificar o subjetivo com o psíquico, e a partir daí se conclui que o psíquico não pode ser objetivo; também se confunde a consciência gnoseológica (como um dos termos da antinomia sujeito-objeto) com a consciência empírica, psicológica, e a partir disto se diz que a consciência não pode ser material.... Como resultado dessa colocação chega-se ao neoplatonismo, dentro do espírito das essências infalíveis, nas quais a existência coincide com o fenômeno. É uma fuga do idealismo que leva a mergulhar nele de cabeça. Já que se teme mais do que ao fogo identificar a existência com a consciência, chega-se assim em psicologia a identificá-las totalmente, numa linha husserliana (Vygotsky, 1996, p. 379-380).

Na verdade, preocupação similar em relação à necessária demarcação entre a esfera ontológica e a gnoseológica, expressou Lukács (1981), em sua Per una Ontologia dell'Essere Sociale, quando, no Capítulo O trabalho, faz referência a Kant, afirmando que o mesmo, no plano metodológico imediato, teria intentado "equacionar e resolver em termos gnoseológicos as questões ontológicas", avaliando que, em perseguindo essa trilha, "no fim, o próprio problema ontológico continua não resolvido" (Lukács, traduzido por Tonet, s/d, p. 9).

As passagens citadas, respectivamente de Vygotsky e Lukács, convergem no sentido de uma preocupação comum com a necessidade de clarear devidamente as relações entre as esferas gnosiológica e ontológica e, mais precisamente, a confusão operada nesse contexto entre qual caminho seguir rumo à compreensão dos complexos do real. Semelhantes preocupações devem ser analisadas, por certo, guardando-se as devidas especificidades acerca da compreensão do problema ontológico pelos respectivos autores.

Conforme vimos aqui indicando, o estudo da obra de Vygotsky, em contraposição à leitura de parte representativa do material produzido por aqueles que dizem pautar-se por suas premissas, e que se auto-intitulam vygotskianos, neovygotskianos, vygotskianos contemporâneos, dentre outras denominações (Duarte, 2000), reforça a nossa tese quanto à relevância da captura do fundamento ontológico do pensamento de Vygotsky, supondo que o mesmo estaria largamente ignorado pelo aglomerado de autores, a exemplo de Oliveira (1997), Rego (1994) e Nogueira (1993), dentre outros, que, pelo obscurecimento da centralidade do trabalho, sobrelevando, em seu lugar, uma ou outra categoria estudada por Vygotsky, desvirtuam o núcleo fundante da psicologia vygotskiana.

Poderíamos dizer, parafraseando o próprio Vygotsky (1996), que estes "tomam o rabo de um sistema e o adaptam à cabeça de outro, intercalando no meio o tronco de um terceiro" ( $p$. 252). Com efeito, as palavras de Vygotsky, destinadas a definir as mais esdrúxulas combinações que se tentaram fazer entre o marxismo e os diferentes ramos da psicologia à sua época, parecem aplicar-se com exatidão às posturas teóricas dos neovygotskianos do nosso tempo. Vejamos como é procedente, consequente e atual a crítica de Vygotsky ao ecletismo científico-metodológico, do qual, caiu vítima, ironicamente, sua própria obra:

\begin{abstract}
As tentativas ecléticas de conjugar elementos heterogêneos, de natureza distinta e de diferentes origens científicas, carecem de caráter sistemático, dessa sensação de estilo, dessa conexão entre nexos que proporciona o submetimento das teses particulares à única ideia que ocupa lugar central no sistema de que faz parte (Vygotsky, 1996, p. 252-253).
\end{abstract}

Nas tramas desse imbroglio eclético, vale insistir, constatamos o deslocamento da categoria trabalho em nome de outras categorias - linguagem, cultura, interação, mediação - que passam a gravitar como centro do sistema 
vygotskiano. Estas terminam por operar um pernicioso desvirtuamento dos conceitos autorados pelo psicólogo soviético, realizando a inclusão de Vygotsky, como anteriormente aludido, no compósito dos modismos pedagógicos contemporâneos, a exemplo do construtivismo, que se opõe diametralmente à perspectiva da transformação socialista da sociedade e do homem, principal horizonte firmado por Vygotsky.

O que está em jogo, aqui, é preciso deixar claro, não é a menção às aludidas categorias per se, mas a condição de centralidade que estas passam oportunisticamente a assumir em sua obra, por sobre as prerrogativas do trabalho, comprometendo a dinâmica e dilacerando a unitariedade do complexo categorial vygotskiano. Ademais, vale assinalar, a colocação aleatória das referidas categorias tem conduzido ao mais completo espontaneísmo pedagógico, condição completamente avessa à compreensão de Vygotsky quanto ao relevante papel que a educação deveria cumprir como um dos instrumentos importantes na formação do novo homem da nova sociedade, o que o levou a declarar que "As novas gerações e suas novas formas de educação representam a rota principal que a história seguirá para criar o homem tipologicamente novo" (Vygotsky, 1998, p. 119).

Ao contrário da forma dominante de aproximação à obra de Vygotsky, reconhecemos nesta, em seus termos próprios, o trabalho como complexo fundante do homem, como ser capaz de desprender-se do determinismo natural, entendendo que todo o conjunto categorial estabelecido pelo autor erige-se a partir de uma interdependência recíproca com aquela que se constitui a categoria central.

Desse modo, declara Vygotsky (1996):

podemos dizer que o animal está totalmente preso à própria natureza, enquanto o homem domina a natureza e a obriga a servir a seus fins. Neste caso, novamente, deve isso ao trabalho. O processo de trabalho exige que o homem tenha certo grau de controle sobre seu próprio comportamento ( $p$. 89).

Neste caso, Vygotsky parece, de fato, estabelecer uma relação de dependência ontológica do comportamento em relação ao trabalho, assim como também o faz, no conjunto de sua obra, em relação à linguagem, ao pensamento, à consciência.

Precisamente em relação à obra Pensamento e Linguagem (2001), seu caminho vai ser trilhado a partir da apreensão do método em Marx, que o leva a conduzir toda a investigação a partir da análise que decompõe em unidades a totalidade complexa, fazendo-o adotar como unidade de análise, a palavra, que, em si, carregaria a síntese que condensa a relação entre o pensamento e a linguagem.

Desse modo, na mesma obra, a análise de Vygotsky avança a partir da crítica rigorosa às principais teorias que explicam a relação entre o pensamento e a linguagem, tomando como exemplo, os trabalhos de Piaget e Stern, sendo oportuno assinalar, de modo mais particular, que, não obstante tenha reconhecido no psicólogo suíço, o mérito de desvelar a admirável ideia de desenvolvimento, cedo identificou que este desviava-se da concepção de fundo que deveria reger a construção de uma psicologia superadora da dicotomia entre as funções psíquicas dos indivíduos e o chão histórico-social em que se radica a gênese e o desenvolvimento humano, findando, então, por destroçar todo o edifício teórico de Piaget, como admitiu o próprio Vygotsky.

Sem pretender esgotar a questão, é oportuno lembrar, com Klein (2005), que, para Piaget, o homem é essencialmente um organismo biológico (certamente capaz de aprender e desenvolver-se formidavelmente em interação com o meio físico e social). Ou, dito de outro modo, Piaget, ao contrário de Vygotsky, traça uma linha contínua entre homem e natureza, não pressupondo uma ruptura entre os fundamentos genético-evolutivos da esfera social em relação à esfera orgânica.

Prosseguindo em sua análise, Vygotsky adentra nas raízes genéticas do pensamento e da linguagem e reconstrói o caminho da relação entre estas duas categorias nos planos da filogênese e da ontogênese, deixando explícita a interferência do papel do trabalho, no desenvolvimento da espécie e do indivíduo.

A respeito da interferência do trabalho no âmbito da ontogênese, Vygotsky realizou uma exaustiva investigação de caráter experimental, da qual despontaram diferentes categorias afins como prática, atividade, ação, as quais, contudo, não assumiram, para nosso psicólogo, identidade com o complexo do trabalho, mas, estabelecendo uma relação ontológica com este, 
desembocaram, como desdobramento, no processo de formação de conceitos, sistematizado, através de diferentes fases que culminam com o amadurecimento do pensamento.

Não é demasiado insistir que, em diferentes passagens de sua obra,Vygotsky deixa registrada, motu proprio, sua compreensão do trabalho como momento fundante do homen, assim como a relação fundante-fundado, estabelecidao pelo psicólogo soviético, entre as diferentes categorias e o complexo do trabalho.

Nessa perspectiva, Vygotsky reporta-se ao significado que se materializa na unidade das duas funções - comunicação e pensamento ocorrido num determinado estágio do desenvolvimento filogenético e ontogenético e que, por sua vez, culmina com o processo de instituição do ser social através dos atos de trabalho.

Desse modo, assevera:

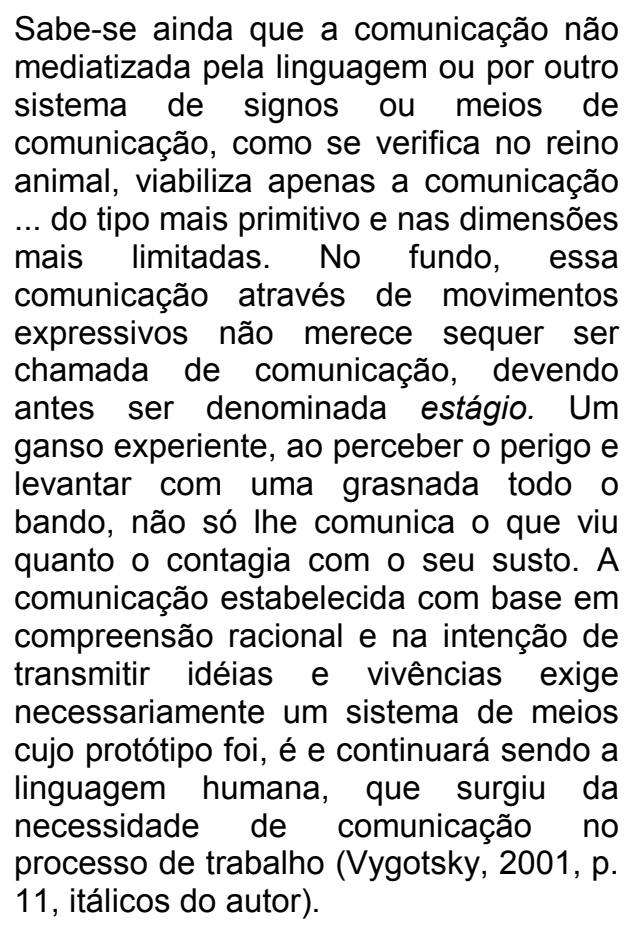

Ressaltando, por seu turno, o fenômeno relativo ao uso dos instrumentos, imprescindível à expansão da esfera de dominação do homem sobre a natureza, pontua:

Antes de controlar o próprio comportamento, a criança começa a controlar o ambiente com a ajuda da fala. Isso produz novas relações com o ambiente, além de uma nova organização do próprio comportamento.
A criação dessas formas caracteristicamente humanas de comportamento produz, mais tarde, o intelecto, e constitui a base do trabalho produtivo: a forma especificamente humana do uso de instrumentos (Vygotsky, 2003, p. 33).

Particularmente a respeito da categoria instrumentos - termo comumente adotado nas traduções brasileiras, ou ferramentas - vocábulo preferencialmente utilizado nas traduções espanholas, é interessante recuperarmos, por princípio, as reflexões de Lukács (1981) quando este define o uso dos instrumentos no ser social, como autoatividade do homem, em outros termos, articulando tal fenômeno ao processo de recuo das barreiras naturais, próprio à constituição do homem como ser social; ao passo que, conforme o autor, a utilização de instrumentos por parte dos animais se impõe em condições de vida marcadas por um caráter artificial ou de cunho passivamente adaptativo.

Como indica a citação anteriormente registrada, como as que se seguirão, abaixo, de caráter análogo, apresenta-se a explicitação de Vygotsky, aqui, ao lado de Luria, acerca da delimitação entre o uso de instrumentos pelos homens e pelos animais.

Referindo-se aos elefantes, por exemplo, demarcam Vygotsky e Luria (1996):

Um elefante quebra galhos de árvores e os utiliza para espantar as moscas. Isso é interessante e instrutivo. Porém, usar galhos para combater as moscas provavelmente não desempenhou nenhum papel considerável na história do desenvolvimento da espécie "o elefante". Os elefantes não se tornaram elefantes pela razão de que seus ancestrais mais ou menos tipo-elefante matavam moscas com galhos ... (p. 88, aspas dos autores).

Mais adiante, Vygotsky e Luria debruçam-se sobre a espécie mais elevada do mundo animal, concluindo, contudo, a exemplo de Lukács, que, mesmo nesse caso, o uso do instrumento acaba por esbarrar no beco sem saída da determinação natural, que, apenas com o ato do trabalho, será rompida.

Assim, explicam os autores:

Na vara usada pelo macaco já podemos ver o protótipo não só de um instrumento em geral, mas de toda uma série de 
instrumentos diferenciados: pás, lanças e assim por diante. Porém, mesmo no caso dos macacos que, no mundo animal, encontra-se no ponto mais elevado quanto ao uso de instrumentos, esses instrumentos ainda não desempenham papel decisivo na luta pela sobrevivência. $\mathrm{Na}$ história do desenvolvimento do macaco, ainda não houve aquele salto para diante que constitui o processo de transformação do macaco em homem.... No processo de desenvolvimento do macaco, esse salto para diante teve inicio, mas não se completou. A fim de que se complete, é preciso que se desenvolva uma forma especial de adaptação à natureza, estranha aos macacos - ou seja, o trabalho (Vygotsky \& Luria, 1996, p. 88).

Assumindo tal posição, Vygotsky encontrase, sem dúvidas, com o sentido rigorosamente marxiano do trabalho como ato-gênese do ser que saltou para adiante da esfera do mundo animal.

Pelo que se estabelece na obra de Vygotsky, podemos, outrossim, assinalar que seu caminho ontológico no sentido marxiano parece firmar-se pelo trato fundamentalmente marxista que atribui à psicologia; e, no limite, por todo o complexo categorial que delimita suas teorizações sobre essência e fenômeno, ser e conhecer, o que, a nosso ver, fica evidenciado com particular clareza, quando o próprio Vygotsky declara, parafraseando Marx:

\begin{abstract}
Se a essência e a forma de manifestação das coisas coincidissem, toda ciência seria desnecessária (K. Marx e F. Engels, Obras, t. 25, parte II, p. 384). Se em psicologia o fenômeno e a existência fossem o mesmo, cada homem seria psicólogo-cientista e a ciência seria impossível, só seria possível o registro. Mas, evidentemente, uma coisa é viver, sentir, e outra estudar, como diz Pávlov (Vygotsky, 1996, p. 384).
\end{abstract}

Vygotsky (1996) depreende de Marx o método que decompõe em unidades a totalidade complexa, entendendo que este "possui todas as propriedades que são inerentes ao todo e, concomitantemente, são partes vivas e indecomponíveis dessa unidade" (p. 374).

Não nos parece, assim, impróprio, assumir que Vygotsky apanha o método de Marx em sua justa acepção: ou seja, como um método que tem por fundamento, a dimensão ontológica, priorizando a totalidade complexa do ser e, com esta, articulando o movimento igualmente complexo de suas partes (vivas).

Retomando os lineamentos gerais de sua produção, podemos atestar, por fim, que Vygotsky se ocupou com incontestável rigor da resolução de questões psicológicas importantes, a exemplo da relação entre pensamento e linguagem; da articulação entre desenvolvimento e aprendizagem; da problemática do comportamento; do sentido da arte. Outros problemas cruciais, propunha-se ainda a enfrentar, com destaque para a categoria da consciência. Assim é que finaliza sua obra máxima, Pensamento e Linguagem (2001), apontando a consciência como um conteúdo, por ele reconhecido como grandioso, a ser explorado em suas investigações posteriores as quais, evidentemente, não puderam avançar, barradas que foram por sua morte prematura. Assim, declarou: "Nossa investigação nos leva diretamente ao limiar de outro problema mais vasto, mais profundo, mais grandioso que o problema do pensamento - a questão da consciência" (Vygotsky, 2001, p. 485).

Tendo em conta o lugar emblemático que ocupa a consciência no arcabouço do marxismo ontológico, no qual desponta como a forma mais desenvolvida da matéria, órgão e médium da subjetividade, como diz Lukács (1981), arriscamo-nos a conceber que o mais instigante na obra de Vygotsky seria, quiçá, o que nesta não aparece de modo explícito. Para além do que foi efetivamente posto, indicações deixadas pelo psicólogo soviético permitem depreender importantes questões apenas esboçadas, mas que pulsam em seus escritos, denunciando, igualmente, conforme nosso exame, a base ontológica do seu complexo categorial.

\section{NOTA CONCLUSIVA}

Reafirmando a conexão do pensamento de Vygotsky com o legado de Marx, estipulada exemplarmente, no Brasil, por Tuleski (2001); Duarte (2000); Martins (2006), dentre outros, inquiririmos sobre as bases ontológicas da psicologia de Vygotsky, aferindo em que medida este assumiria uma visão ontologicamente perspectivada acerca da essência humana, conforme explicitado por Lukács, a partir de Marx. 
Referido movimento analítico repousou na compreensão de que o resgate da natureza ontológica do marxismo posicionou o legado marxiano na contra corrente das distorções imputadas ao pensamento de Marx no curso da história.

Para tanto, em paralelo à explicitação ontológica elaborada por Lukácse, sem deixar de ir ao encontro da letra de Marx, enfrentamos o exame dos textos de Vygotsky, privilegiando sua obra mais madura, Pensamento e Linguagem, apelando, em menor escala, a outros estudos selecionados do autor, que atestam, de forma mais direta sua vinculação com a premente questão da formação do novo homem socialista, associada à crise da psicologia do seu tempo, cuja natureza não consegue se desalinhar das alternativas antimaterialistas.

Com base em nossa investigação, inferimos que o fato de Vygotsky não ter propalado de modo explícito o problema ontológico não significa que sua psicologia esteja isenta de um pressuposto de natureza ontológica. Nesse sentido, postulamos que, consoante a essa perspectiva, não hesita Vygotsky ao demarcar a essência radicalmente histórica do homem, indicando o trabalho como momento decisivo que opera a passagem do ser meramente biológico ao ser social, trazendo à luz uma nova esfera ontológica, na qual impera, igualmente, um novo tipo de atividade vital, qual seja, a atividade transformadora, porquanto livre e consciente. Estabelece, assim, em seus termos próprios, a relação fundante-fundado, entre trabalho e linguagem, concebendo, portanto, esta última categoria tão cara a suas investigações, em vinculação ontogenética com a atividade prática dos homens. Os escritos de Vygotsky atestam, ademais, que este ergueu todo seu complexo categorial sobre a possibilidade da emancipação humana, condição somente possível de forma cabal no terreno da ontologia.

$\mathrm{Na}$ verdade, no caminho de volta da investigação, deparamo-nos frontalmente com a discussão ontológica, exposta, contraditoriamente, através de uma aberta declaração anti-ontológica de Vygotsky. Aqui, novamente arriscamo-nos a pressupor que a explícita aversão de Vygotsky à apropriação ontológica ordinariamente operada quanto à obra de Marx se explicaria, em última instância, a partir dos elementos metafísicos por ele evidenciados na ontologia que lhe é possível enxergar, o que nos faz postular, por conseguinte, que a ontologia no sentido marxiano do termo, recuperada do legado de Vygotsky somente seria possível post festum, com aporte nas indicações de Lukács, a quem coube, décadas à frente, o empreendimento de resgatar em Marx, a verdadeira ontologia, aquela antimetafísica ontologia do ser social.

Em suma, nossos estudos indicam que a ontologia de Vygotsky, consolidada, em última instância, na centralidade aferida à categoria trabalho, conjugada à afirmação da possibilidade da emancipação humana, abre-se como um campo profícuo para futuras investigações, considerando-se toda a complexidade da questão, sobre a qual, pretendemos ter apresentado, aqui, um esboço consistente, ainda que introdutório.

\section{REFERÊNCIAS}

Burgess, T. (1994). Ler Vygotsky. In: DANIELS, H. (org.) Vygotsky em foco: pressupostos e desdobramentos. São Paulo: Papirus.

Costa, F. (2010). O pensamento ontológico de Marx e os desafios da luta de classes no século XXI. In S. Jimenez, J. Rabelo e M. D. Mendes Segundo (Orgs.). Marxismo, educação e luta de classes: pressupostos ontológicos e desdobramentos ídeo-políticos. Fortaleza: EDUECE.

Duarte, N. (2000). Vigotski e o "Aprender a Aprender": Crítica às Apropriações Neoliberais e Pós-Modernas da Teoria Vigotskiana. São Paulo: Autores Associados.

Elhammoumi, M. (2010). Is back to Vygotsky enough? The legacy of socio-historicocultural psychology. Psicologia em Estudo 15 (4), 661673. Recuperado em 16 de outubro de 2012, de http://www.scielo.br/pdf/pe/v15n4/v15n4a01.pdf

Klein, L. R. (2005). Construtivismo piagetiano: considerações críticas à concepção de sujeito e objeto. In N. Duarte (Org.), Sobre o construtivismo. São Paulo: Autores Associados.

Lessa, S. (1996). A ontologia de Lukács. Maceió: EDUFAL.

Lukács, G. (1981). Per uma ontologia dell'essere sociale. Roma: Editora Riuniti.

Lukács, G. (2011). Prolegômenos para uma ontologia do ser social. São Paulo: Boitempo.

Lukács, G. (s/d). O Trabalho. In Per una ontologia dell'essere sociale, Capítulo I, Tomo II. Tradução de Ivo Tonet recuperada em 13 de outubro de 2012, de http://www.scribd.com/doc/59459867/OTrabalho-Lukacs\#fullscreen 
Mainardes, J. e PINO, A. (2000). Publicações brasileiras na perspectiva vigotskiana. Educação \& Sociedade, (21),71, 255-269.

Martins, S. T. F. (2006). Aspectos teóricometodológicos que distanciam a perspectiva sócio-histórica vigotskianado construtivismo piagetiano. In S. G. L Mendonça e S. Miller (Orgs.), Vigotski e a escola atual: fundamentos teóricos e implicações pedagógicas. Araraquara: Junqueira\&Marin.

Marx, K. (1989). O Capital (Livro 1, v. I). Rio de Janeiro: Bertrand Brasil. (Original publicado em 1867).

Newman, F. e Holzman, L.(2002). Lev Vygotsky: cientista revolucionário. São Paulo: Edições Loyola.

Nogueira, A. L. H. (1993). Eu leio, ele lê, nós lemos: processos de negociação na construção da leitura. In: Smolka, A. L. B. e Góes, M. C. R. (orgs.). A linguagem e o outro no espaço escolar: Vygotsky e a construção do conhecimento. Campinas: Papirus.

Oldrini, G. (1999). Gramsci e Lukács, adversários do marxismo da Segunda Internacional. Crítica Marxista (8), 67-80. Recuperado em 10 de setembro de 2012, de http://www.ifch.unicamp.br/criticamarxista/arquivo s_biblioteca/artigo56critica8parte5oldrini.pdf

Oliveira, M. K. (1997). Vygotsky: aprendizado e desenvolvimento, um processo sócio-histórico. São Paulo: Scipione.

Rego, T. C. (1994). Vygotsky: uma perspectiva histórico-cultural da educação. Petrópolis: Vozes.

Tertulian, N. (1996). Uma apresentação à Ontologia do ser social, de Lukács. Crítica Marxista (3), 5469. Recuperado em 20 de junho de 2012, de http://www.ifch.unicamp.br/criticamarxista/arquivo s_biblioteca/artigo183_Tertulia.pdf
Tuleski, S. C. (2001). Vygotsky: a construção de uma psicologia marxista. Maringá: Eduem.

Vigotski, L. S. (1998). La modificación socialista del hombre, In La genialidad y otros textos inéditos. Buenos Aires: Almagesto, 1998, p.109-125. (Original publicado em 1930).

Vygotsky, L. S. (2003). A formação social da mente: o desenvolvimento dos processos psicológicos superiores. São Paulo: Martins Fontes. (Original publicado em 1931).

Vygotsky, L. S. (1996). Teoria e método em psicologia. São Paulo: Martins Fontes. (Manuscrito originalmente concluído em 1924).

Vygotsky, L. S. (1999). O significado histórico da crise da psicologia: uma investigação metodológica. In Teoria e Método em Psicologia (2 $2^{\mathrm{a}}$. Edição). São Paulo: Martins Fontes. (Manuscrito original redigido em 1926/1927).

Vygotsky, L. S. (2001). Pensamento e linguagem. São Paulo: Martins Fontes. (Original publicado em 1934).

Vygotsky, L. S. e Luria, A. R. (1996). Estudos sobre a história do comportamento: símios, homem primitivo e criança. Porto Alegre: Artes Médicas. (Original publicado em 1930).

Recebido em 17/04/2013 Aceito em 22/08/2013

Francisca Maurilene do Carmo: doutora em Educação Brasileira pela Universidade Federal do Ceará, professora da Universidade Federal da Paraíba, pesquisadora do Instituto de Estudos e Pesquisas do Movimento Operário IMO/UECE.

Susana Vasconcelos Jimenez: PhD em Educação, professora da Universidade Estadual do Ceará, diretora do Instituto de Estudos e Pesquisas do Movimento Operário (IMO/UECE). 